http://www.diva-portal.org

\title{
Postprint
}

This is the accepted version of a paper published in Midwifery. This paper has been peerreviewed but does not include the final publisher proof-corrections or journal pagination.

Citation for the original published paper (version of record):

Ulfsdottir, H., Saltvedt, S., Ekborn, M., Georgsson, S. (2018)

Like an empowering micro-home: A qualitative study of women's experience of giving birth in water

Midwifery, 67: 26-31

https://doi.org/10.1016/j.midw.2018.09.004

Access to the published version may require subscription.

N.B. When citing this work, cite the original published paper.

License information: https://creativecommons.org/licenses/by-nc-nd/4.o/

Permanent link to this version:

http://urn.kb.se/resolve?urn=urn:nbn:se:shh:diva-3116 


\section{Like an empowering micro-home: a qualitative study of women's experience of giving birth in water}

Authors: Hanna Ulfsdottir RNM, PhD student ${ }_{\mathrm{a}}$, Sissel Saltvedt, MD, PhD , Marie Ekborn $_{\mathrm{c}}$ RNM and Susanne Georgsson, RNM, Associate Professor ${ }_{d}$.

${ }_{\mathrm{A}}$ Department of Clinical Science and Education, Karolinska Institutet, Stockholm Sweden, Sophiahemmet University, Box 5605, SE-114 86 Stockholm, Sweden, Lecturer.

${ }_{\mathrm{B}}$ Department of Women's and Children's Health (KBH), Karolinska Institutet, Stockholm Sweden, MD.

c Karolinska University Hospital Huddinge, SE-141 86 Stockholm, Sweden.

${ }_{D}$ Department of Clinical Science Intervention and Technology, Karolinska Institutet, Stockholm Sweden, Sophiahemmet University, Box 5605, SE-114 86 Stockholm, Sweden, Head of University Department.

\section{Corresponding author:}

Hanna Ulfsdottir

Sophiahemmet Högskola, Lindstedtsvägen 8, PO Box 5605,SE-114 86 Stockholm, Sweden.

Email: hanna.ulfsdottir@shh.se

\section{Conflict of interest statement}

The authors declare that there is no conflict of interests.

\section{Ethical approval}

The study has ethical approval

\section{Funding}

This study was supported by a grant from Sophiahemmet Foundation for Clinical Research. 


\begin{abstract}
Objective: To describe women's experiences and perceptions of giving birth in water.

Design: A qualitative study with in-depth interviews three to five months after the birth. A content analysis of the interviews was made.

Setting: One city-located hospital in Stockholm, offering waterbirth to low risk women. Participants: 20 women, 12 primiparas and 8 multiparas, aged 27-39.

Measurements and findings: The overall theme emerging from the analysis was, "Like an empowering micro-home", which describes the effect of being strengthened, enabled and authorized in the birth process. Three categories were found: "Synergy between body and mind", "Privacy and discretion", and "Natural and pleasant".

Key conclusions: The immersion in warm water provided the women with conditions that helped them to cope and feel confident during labour and birth. The homelike and limited space of a bathtub helped give a relaxed feeling of privacy, safety, control and focus for the women.

Implications for practice: This study contributes to a deeper understanding of what waterbirth offers to women. For some women, waterbirth may be a way to accomplish an empowering and positive birth experience, and could work as a tool that preserves the normality of, and increases self-efficacy in, childbirth.
\end{abstract}

\title{
Keywords
}

Birth, Water immersion, Experience of childbirth, Waterbirth, Empowerment, Content Analyses 


\section{Introduction}

The childbirth experience is described as a significant life event (Larkin et al., 2009), and has an impact on a woman's wellbeing, attachment to her child, her self-esteem, breastfeeding as well as on the planning of future pregnancies (Gayiti et al., 2015, Brown and Jordan, 2013, Gottvall and Waldenstrom, 2002, Andersen et al., 2012). The extent of satisfaction with childbirth is a relevant indicator for the quality of maternity care (Hodnett, 2002).

Factors frequently mentioned as being important for women's experience of childbirth are pain and a sense of control (Larkin et al., 2009). Being in control in this context includes both personal control of the situation as well as a sense of involvement in the birth process (Waldenstrom, 1999, Goodman et al., 2004). Previous studies of waterbirths have shown that sense of control has a prominent role in women's perceptions of giving birth in water. Further, pain relief, relaxation, a calming, supporting feeling from the water and less interference have been reported by women giving birth in water (Richmond, 2003, Maude and Foureur, 2007, Wu and Chung, 2003). A Danish follow-up study, including 905 primiparas, found that risk factors for reporting a less positive birth experience five years after childbirth were: having an epidural, less use of water as pain relief, or not having a spontaneous vaginal delivery (Maimburg et al., 2016). Women who choose waterbirth are often reported as doing so to experience a more natural birth with fewer interventions (Garland, 2010), which also can affect the birth experience (Waldenstrom, 1999, Bibeau, 2014).

Empowerment is a complex concept; fundamentally it is about gaining power and ability in a way that increases capacity, self-efficacy, and decision making. Empowerment is associated with childbirth in different aspects (Hardin and Buckner, 2004, Lindgren and Erlandsson, 
2010, Dahlberg and Aune, 2013, Walsh and Devane, 2012, Prata et al., 2017); used in this context it has both psychological and social domains (Cattaneo and Chapman, 2010).

Waterbirth has not been offered in Swedish hospitals for the past few decades as the safety of the newborn has been disputed. Lately, there has been increased interest in giving birth in water, although there is a lack of Swedish studies within this field. Among midwives there is a lack of experience and insufficient knowledge about women's experiences of waterbirth. The purpose of this study was to describe women's experiences and perception of giving birth in water.

\section{Methods}

We conducted a qualitative study with 20 in-depth interviews. An inductive approach was chosen as the purpose was to extend knowledge without a given hypothesis (Elo and Kyngas, 2008). Twenty interviews were regarded as sufficient in terms of information power due to the rather narrow aim, the sparse specificity and the few previous studies on women's' experiences of waterbirths (Malterud et al., 2015).

\section{Data collection}

The women who had a waterbirth, from March 2014 to March 2015, at the clinic in Stockholm providing such facilities, were identified from the birth records They were contacted by post to obtain informed consent about a quantitative study on waterbirth in the frame of the research project "To give birth in water". At the same time, they were able to give consent to being contacted for an interview for the present qualitative study. Of the 162 women returning the informed consent form for the quantitative study, $145(90 \%)$ stated their 
telephone number and agreed to be contacted. Women who gave birth within five months were eligible for the interview as the experience and memories of childbirth could alter over time (Waldenstrom, 2004). Of the 74 eligible women, 20 were randomly selected to be interviewed. Before contacting the selected women, we ensured that both primi- and multiparas were represented. The women chose where to be interviewed; eighteen women were interviewed at home and two preferred to come to the university.

An interview guide divided into themes to illustrate different aspects was developed. The interview guide was developed by two of the authors (HU and SG) and was reviewed by five colleagues. It was first tested as a pilot with one interview and evaluated by HU and SG. The pilot interview revealed rich and useful data according to the aim of the study and was included in the analysis. The interviews were like conversations and the interview guide was used only as a basis. Supplementary questions were asked to help women develop their answers when needed. The interviews were undertaken during 2015 by $\mathrm{HU} n=14$, and $\mathrm{ME}=6$, both experienced midwives with former experience of interviewing. The interviews were digitally recorded and lasted between 30-70 minutes.

Settings and participants

All women interviewed lived in the Stockholm area and gave birth at one specific city hospital with approximately 3,300 births per year. This clinic provided woman-centred care and, to a large extent, continuous support during active labour. The clinic had a bathroom adjacent to each delivery room with corner baths that allowed the possibility to move and change position. Most women were not aware of the option of waterbirth until arriving at the maternity ward. Of the 20 women, 12 were primiparas, and 8 were multiparas and their median age was 33 (min-max 27-39). Of the multiparas, the parity varied from 1-7 with a 
median of one. Data about civil- and educational status were available for 17 women. All these 17 women were in co-habitation with the baby's father and about half of them had an occupation requiring a university education.

Ethical considerations

The Regional Ethical Review Board in Stockholm approved the study DNR: 2014/2077-31.

Data analysis

Qualitative content analysis was chosen with the purpose of making valid inferences from the text and to distil words into themes that share the same meaning and describe a phenomenon. In content analysis, a category can be used to answer the question, "What?" and a theme to answer the question, "How?" (Krippendorff, 2013). A theme can also be defined as threads of meaning that recur on an interpretative level in the text (Graneheim and Lundman, 2004, Polit and Beck, 2012). To find this underlying meaning, a latent approach was chosen (Elo and Kyngas, 2008). As a practical guide for the steps in the analysis, Graneheim and Lundman was used (2004).

The recorded interviews were transcribed verbatim and read several times to obtain a sense of the whole. Throughout the analysis, the researcher should be aware of her/his understanding of, and familiarity with, the phenomena. According to Krippendorff (2013), familiarity is necessary in order to capture important nuances and underlying meanings (Krippendorff, 2013). The next step was to identify meaning units and condense them. The first analysis was carried out manually, but for the second, NVivo 11 Starter, a software tool for organizing and analysing qualitative data, was used. 
Table 1 Examples of coding from meaning unit

\begin{tabular}{|l|l|l|}
\hline Meaning unit & Condensed meaning unit & Code \\
\hline $\begin{array}{l}\text { "It went from feeling totally } \\
\text { tense due to pain in the } \\
\text { muscles....especially in the } \\
\text { back, that spread to the } \\
\text { whole body. I know that I } \\
\text { tried to think of relaxing my } \\
\text { jaw...so immersing in the } \\
\text { warm water, covering every } \\
\text { centimetre...the muscles } \\
\text { relaxed in my whole body." }\end{array}$ & $\begin{array}{l}\text { Going from tense to relaxed } \\
\text { muscles in the whole body }\end{array}$ & Physical relaxation \\
\hline $\begin{array}{l}\text { "It's a great way I think to } \\
\text { reduce stress..." }\end{array}$ & A way to reduce stress & Stress relief \\
\hline $\begin{array}{l}\text { "No nitrous oxide, no sterile } \\
\text { water injections, thus } \\
\text { nothing! I could not...and I } \\
\text { can still hardly fathom it. I } \\
\text { think it's so amazing! That } \\
\text { the body could handle all } \\
\text { this! }\end{array}$ & No need for other pain relief & Pain relief \\
\hline $\begin{array}{l}\text { "It was very easy after the } \\
\text { birth as well. You don't have } \\
\text { all the disgusting...it } \\
\text { vanished automatically in } \\
\text { the water." }\end{array}$ & basily and practical after & Practical \\
\hline
\end{tabular}

The meaning units were coded close to the text and contained mostly nouns like: focus, warmth, relaxation, pain relief, mobility, demarcation and buoyancy effect. After coding and re-coding several times, the final codes were clustered depending on how they related to each other. These clusters resulted in sub-categories and categories which were discussed in the research group. In all steps, the original transcripts were referred to several times to ensure that the results reflected the whole, and maintained the validity of the text. This was facilitated 
by NVivo. The informants were given numbers that are written after each quotation in the findings.

Table 2. The findings of the analysis

\begin{tabular}{|c|c|c|}
\hline Subcategory & Category & Theme \\
\hline $\begin{array}{l}\text { Increased focus and control } \\
\text { over the body }\end{array}$ & \multirow{5}{*}{$\begin{array}{l}\text { Synergy between body and } \\
\text { mind }\end{array}$} & \multirow{11}{*}{$\begin{array}{l}\text { Like an empowering } \\
\text { micro-home }\end{array}$} \\
\hline Mental relaxation & & \\
\hline $\begin{array}{l}\text { Pain relief and physical } \\
\text { relaxation }\end{array}$ & & \\
\hline $\begin{array}{l}\text { Buoyancy effect facilitating } \\
\text { mobility }\end{array}$ & & \\
\hline $\begin{array}{l}\text { Autonomous second stage of } \\
\text { labour }\end{array}$ & & \\
\hline Less exposed and bare & \multirow{3}{*}{ Privacy and discretion } & \\
\hline Homelike and less clinical & & \\
\hline $\begin{array}{l}\text { A free-zone- feeling of being } \\
\text { safe and secure }\end{array}$ & & \\
\hline Comfortable and practical & \multirow[b]{3}{*}{ Natural and pleasant } & \\
\hline Gentle transition for the baby & & \\
\hline Natural & & \\
\hline
\end{tabular}

\section{Findings}

The overall theme that emerged as a common thread during the analysis was: Like an empowering micro-home. Three categories describing the women's experiences and perceptions of waterbirth were found: Synergy between body and mind, Privacy and discretion, and Natural and pleasant.

Like an empowering micro-home

An empowering micro-home describes the effect of being strengthened, enabled and authorized in the birth process. Without direct guidance, the immersion in water provided the 
women with conditions that helped them to cope and feel confident during labour and birth. The pain relief and relaxation had a cushioning effect which made the contractions easier to manage. The feelings of privacy, discretion and it being home-like, heightened the perception of being in control and not handing oneself over to the clinic. The demarcation of the bath tub and the mass of the water made them feel protected and less exposed which also seemed to have an empowering effect.

Synergy between body and mind

The women described both mental and physical feelings and experiences that originate from the perception of labouring and giving birth in water. Most of the experiences and perceptions interacted with one another and affected the women in an upward spiral that made the contractions easier to handle and the experience of birth positive.

\section{Mental relaxation and increased focus and control over the body}

The mental relaxation seemed to lead to an increased control over, and focus upon, the body. "You experience that you have more control over your own body when you are in water." (Interview \#6). Being immersed in water appeared to help the woman concentrate on, and cooperate with, her body, not work against it. One woman described the water "as a lubricant for her brain" (Interview \#5). The mental relaxation facilitated guidance regarding how to handle the contractions and gave a feeling of autonomy in the situation. One description referred to "shifting from the passenger seat to the driver's seat" (interview \#6). Another likened the recognition of coping with labour to "finding a rhythm and breathing during strenuous exercise" (Interview \#3).

"This thing about timing the contractions, eh... it was just chaos. And that was what changed when I arrived and when I got down into the bath. It became more obvious. The whole labour became, it dawned on me how I could manage it, even if nobody told me." (Interview \#16) 
All women described some degree of positive change in the experience of pain but the perception of warm water as an actual analgesic varied. Some of the women combined immersing in water with nitrous oxide. Several women were surprised and overwhelmed by the fact that the bath helped them to give birth without epidural anaesthesia, which was their original plan.

"It was a quite a big difference. Because there was not that intense, the powerful (pain)... that never appeared. Of course, it hurt but it cushioned one more than you can imagine. So, to be in warm water, so incredible. So natural pain relief." (Interview \#14)

Many women described the physical feeling of relaxation provided by the warm water as an indirect route to pain reduction, and not a pain-relieving effect of the water itself.

Others described how being able to relax during the pauses, and the buoyancy effect gave them a sense of ease and pain relief. The ponderous pregnant body suddenly became less heavy when the strain diminished and made it easier to shift position. Many women described how they were swinging by themselves in the water during the contractions which also contributed to relieving the pain.

"It's just being able to move and not be clumsy. Because in the end, I mean of the pregnancy, you are pretty heavy. So, I was really happy to be able to twist and turn and relax and the warmth. That is really nice and you can feel it in your whole body, so it was... and that is the greatest advantage...that you can move as you want to.” (Interview \#12)

\section{Autonomous second stage of labour}

The experience of pain relief by water in the second stage varied. Most women experienced some pain relief when pushing, but this was not obvious to many of the primiparas as they had no previous birth with which to compare. Some women described the relaxation between the contractions in the second stage as most helpful, but the pain during contractions was still intense. Several women described empowerment in the moment of birth which was described 
as calm and controlled. Further, they felt aware of what to do and did not need much guidance from the midwives. "Then the head was crowning, and the midwife asked if I wanted to take my baby out myself. And I got to do that, and it was so cool to pull up my baby and then we were lying there together" (Interview \#13).

Many women also reported that they felt strong and powerful throughout labour due to the buoyancy effect and the ability to relax during the first stage of labour. This made the experience of the second stage of labour easier and less tiring. "I think that being in water in the first stage of labour saved me lots of energy for the pushing phase, because labour is so favourable in water compared to being above water" (Interview \#16).

Privacy and discretion

The environment and demarcation of the bathtub were described by many like having their own sphere that felt safe and gave a recognition of home, privacy and "far from white coats and scalpels" (Interview \#2).

\section{Less exposed and bare}

Lying in a bathtub, even if being naked, seemed to give a feeling of discretion due to the physical demarcation. "What I did feel was that I didn't feel so naked as I was. I felt protected" (Interview \#1). Comparisons were made with laying in a bed at eye level, which made the women feel bare, exposed and not knowing what to do with their arms and legs. They described experiencing physical protection by the mass of the water and the tub, with the latter giving a feeling of being concealed and shielded.

"Yes, it was like lying in my own womb with the water against my body from all directions, like in a small corner, or nest perhaps - staying warm and I had good contact with my partner. I felt a little protected and then you avoid feeling totally exposed and bare" (Interview \#4).

\section{Homelike and less clinical}


The women described the bathtub as a nest, a micro-home or a uterus where they felt secluded and safe. Since a bathtub is something you have at home; the feeling of a less clinical and more cosy, homelike environment was described by many women. "It felt less clinical. It felt like you could have been in a bathtub at home" (Interview \#5).

The bathtub was placed in a bathroom, connected to the delivery room, which housed medical equipment, and this was described as positive. "Then all signs of a hospital environment were gone. Everything was gone. It was quiet, and there was us and there was water. It was amazing" (Interview \#13).

\section{A free-zone-feeling of being safe and secure}

The water and the tub were perceived as barriers and a shelter from the rest of the world. This barrier was not only physical but was described as feeling cherished and protected. " I think you withdraw from the rest of the world in some way. That is also how it works when you take a bath, you get time for yourself exclusively" (Interview \#2).

Descriptions of privacy and that they had their own safe haven or free-zone occurred together with feelings of being hugged, pampered and nurtured. "Yes, it's like your own little zone, that bathtub becomes like a shelter" (Interview \#11).

Natural and pleasant

Even though 18 of the 20 women had not planned for a waterbirth, most of them reported that it was a self-evident choice to stay in the water when first being immersed. "It just felt natural in some way. The warmth and...it felt kind to the body somehow" (Interview \#17).

A feeling that this was a great and natural way to give birth for both them and their child, instead of having medical anaesthesia was mentioned by many. However, some considered coming up to have an epidural at some time but were content with not doing so. "It felt like this was giving birth for real. Last time I was totally anesthetized” (Interview \#10). 


\section{Gentle transition for the baby}

Immersing in warm water was described as a smooth and pleasant transition for mum and baby which optimized labour and birth. For the baby, some mothers described the transition as gentle, coming from the amniotic water in the womb into the water in the tub. "I think it changes the experience for the baby. It's good for the baby to go from water to water. It makes sense to me" (Interview \#1).

Many describe the cosy and snuggly feeling of laying in the bath with their baby on their chest immediately after birth. "I also think that maybe it was nice for the baby...that it was not as shocking for her to come out" (Interview \#18).

\section{Comfortable and practical}

There were also descriptions of the comfort and practical advantages of skipping the elements of stretching and shifting the sheets and having blood all over oneself and the baby during and after the birth. "When he came out it felt very smooth. He came from the water and right up on me, and you could wash away a little blood with the water" (Interview \#9).

There were also comments about having everybody near, both partner and midwife who were beside the tub. Some women wished to stay longer in the bath afterwards and felt interrupted when they had to leave the tub. "It was fantastic. I can only imagine being in a stiff chair where it is cold and uncomfortable" (Interview \#13).

\section{Discussion}

Empowerment through the birth process, facilitated by the positive synergy effect between body and mind, emerged in descriptions of the complex event of labour and birth. The immersion in warm water and the homelike and limited space of a bathtub - "micro-home", 
helped giving a relaxed feeling of privacy, safety and focus for the women, which seemed strengthening. A feeling of stress relief and relaxation coming from immersing in warm water has been shown in previous studies (Benfield et al., 2010, Benfield, 2002, Grossman et al., 1992). This can induce a sense of control and flow in coping with labour, which also contributed to empowerment. The physical effects of warmth cause muscle relaxation and increase blood circulation to the body and the uterus (Weston et al., 1987). This may reduce ischemia which is one of the main causes of pain during labour (Labour and Maquire, 2008). Having a relaxed body and mind is most helpful when managing contractions, and in this way a loop of positive effects was perceived.

Empowerment is linked to self-efficacy which is related to the ability and capacity to cope and manage in a specific situation or challenge (Cattaneo and Chapman, 2010). The women described a sense of focus and being in control, and participation at the same time as they followed their body. The experience of simultaneously being in control and letting go of control has been described previously (Lundgren, 2005). In several studies, a sense of being in control has been associated with satisfaction with childbirth (Goodman et al., 2004; Lavender et al., 1999; Karlstrom et al., 2015) and is also featured in descriptions of what immersing in water offers women (Maude and Foureur, 2007; McKenna and Symon, 2014; Richmond, 2003). In this regard, control probably refers to both personal control and involvement such as shared decision-making (Gibbins and Thomson, 2001).

Interventions, like augmentation with oxytocin and amniotomy, have been associated with negative experiences of childbirth and can also affect the postpartum period and breastfeeding (Waldenstrom, 1999; Kroll-Desrosiers et al., 2017; Nilsson, 2014; Bibeau, 2014; K Cadwell, 2017). The free-zone or barrier to the outside world, described by the women, may also create a barrier to unnecessary interventions and examinations from midwives (Ulfsdottir et al., 2017; Garland, 2010; Cluett et al., 2004). It could be a way to de-medicalise normal birth and 
contribute to enabling, and empowering women in similar way as has been seen in home births (Bernhard et al., 2014, Lindgren and Erlandsson, 2010). As mentioned, prior to arriving at the maternity ward, 18 of the 20 participating women had not planned, or been aware of the option of giving birth in water. The findings of accomplishment of birthing without analgesia, and "birthing by themselves" meaning that they were in charge, was expressed by many of the women. Several women had planned for an epidural and were surprised and overwhelmed by the experience of giving birth without it. Waterbirth became a positive way of giving birth though they did not have a pronounced opinion about interventions in advance. These circumstances differ from other studies, undertaken in Birth Centres, where women often aspire to a natural birth or a waterbirth and may be a more selected group (Hardin and Buckner, 2004, Wu and Chung, 2003).

The fact that a bathtub is associated with a domestic milieu and not a clinical one and technical seemed to be of significance. Many illustrative images were used describing the safe and protected feeling of lying in the bathtub, which seemed to strengthen the normality of giving birth. The importance of the environment in the birth experience has been described previously (McKinnon et al., 2014, Nilsson, 2014).

In these interviews, almost no disadvantages of waterbirth were described. One possible explanation for the low number of negative responses is that women who do not find it a positive experience to immerse themselves in water have no reason to stay in it and are not likely to have a waterbirth. When asking for disadvantages, one woman described that she felt cold after birth, one was concerned that the tub water was unclean, and one felt uncomfortable on leaving the bath tub.

This study is based on the experience of immersing in water during both the first and second stages of labour with no distinct separation. Despite this, the second stage of labour resulted in its own subcategory - Autonomous second stage of labour. In this subcategory, the 
experiences specifically concern the actual pushing and birth, where the effects of immersing are somewhat more disparate. However, the women describe that immersing in the first stage of labour affected their experience of the second stage of labour. The subcategory, Autonomous second stage of labour, is in accord with, and contains, all the other parts of the analysis - both subcategories and the theme.

\section{Limitations}

This study was carried out in at a clinic in Stockholm where the women, to a large extent, had continuous support during labour, which also contributes to a positive birth experience (Bohren et al., 2017). It is conceivable that the group of women participating in the study may be the ones who, before labour, had positive expectations and high self-efficacy, and that women who had a negative experience did not agree to be interviewed. In this setting, 145 women out of 162 agreed to be interviewed.

To have two interviewers, could mean different approaches and interview techniques, which could be a weakness. An interview guide was used to cover different areas and to help counteract eventual differences. The two interviewers both had previous experience of interviewing.

\section{Conclusion}

Immersion in warm water provided the women with conditions that helped them to cope and feel confident during labour and birth. The pain relieving, and relaxation gave synergy effects between body and mind which empowered and strengthened them. The homelike and limited 
space of a bathtub helped to give a feeling of privacy, safety, control and focus for the women.

Implications for practice

This study contributes to a deeper understanding of what waterbirth offers to women. For some women, waterbirth may be a way to accomplish an empowering and positive birth experience and could work as a tool that preserves the normality of, and increases selfefficacy in, childbirth.

\section{References}

Andersen, L. B., Melvaer, L. B., Videbech, P., Lamont, R. F., \& Joergensen, J. S. (2012). Risk factors for developing post-traumatic stress disorder following childbirth: a systematic review. Acta Obstet Gynecol Scand, 91(11), 1261-1272. doi:10.1111/j.1600-0412.2012.01476.x

Benfield, R. D. (2002). Hydrotherapy in labor. J Nurs Scholarsh, 34(4), 347-352.

Benfield, R. D., Hortobagyi, T., Tanner, C. J., Swanson, M., Heitkemper, M. M., \& Newton, E. R. (2010). The effects of hydrotherapy on anxiety, pain, neuroendocrine responses, and contraction dynamics during labor. Biol Res Nurs, 12(1), 28-36. doi:10.1177/1099800410361535

Bernhard, C., Zielinski, R., Ackerson, K., \& English, J. (2014). Home birth after hospital birth: women's choices and reflections. J Midwifery Womens Health, 59(2), 160-166. doi:10.1111/jmwh.12113

Bibeau, A. M. (2014). Interventions during labor and birth in the United States: a qualitative analysis of women's experiences. Sex Reprod Healthc, 5(4), 167-173. doi:10.1016/j.srhc.2014.10.003

Bohren, M. A., Hofmeyr, G. J., Sakala, C., Fukuzawa, R. K., \& Cuthbert, A. (2017). Continuous support for women during childbirth. Cochrane Database Syst Rev, 7, Cd003766. doi:10.1002/14651858.CD003766.pub6

Brown, A., \& Jordan, S. (2013). Impact of birth complications on breastfeeding duration: an internet survey. J Adv Nurs, 69(4), 828-839. doi:10.1111/j.1365-2648.2012.06067.x

Cattaneo, L. B., \& Chapman, A. R. (2010). The process of empowerment: a model for use in research and practice. Am Psychol, 65(7), 646-659. doi:10.1037/a0018854

Cluett, E. R., Pickering, R. M., Getliffe, K., \& St George Saunders, N. J. (2004). Randomised controlled trial of labouring in water compared with standard of augmentation for management of dystocia in first stage of labour. Bmj, 328(7435), 314. doi:10.1136/bmj.37963.606412.EE

Dahlberg, U., \& Aune, I. (2013). The woman's birth experience---the effect of interpersonal relationships and continuity of care. Midwifery, 29(4), 407-415.

doi:10.1016/j.midw.2012.09.006 
Elo, S., \& Kyngas, H. (2008). The qualitative content analysis process. $J$ Adv Nurs, 62(1), 107-115. doi:10.1111/j.1365-2648.2007.04569.x

Garland, D. (2010). Revisiting Waterbirth: An attitude to care. United Kingdom: palgrave Mc Millan.

Gayiti, M. R., Li, X. Y., Zulifeiya, A. K., Huan, Y., \& Zhao, T. N. (2015). Comparison of the effects of water and traditional delivery on birthing women and newborns. Eur Rev Med Pharmacol Sci, 19(9), 1554-1558.

Gibbins, J., \& Thomson, A. (2001). Women's expectations and experiences of childbirth. Midwifery, 17. doi:10.1054/midw.2001.0263

Goodman, P., Mackey, M. C., \& Tavakoli, A. S. (2004). Factors related to childbirth satisfaction. $J$ Adv Nurs, 46(2), 212-219. doi:10.1111/j.1365-2648.2003.02981.x

Gottvall, K., \& Waldenstrom, U. (2002). Does a traumatic birth experience have an impact on future reproduction? BJOG, 109(3), 254-260.

Graneheim, U. H., \& Lundman, B. (2004). Qualitative content analysis in nursing research: concepts, procedures and measures to achieve trustworthiness. Nurse Educ Today, 24(2), 105-112. doi:10.1016/j.nedt.2003.10.001

Grossman, E., Goldstein, D. S., Hoffman, A., Wacks, I. R., \& Epstein, M. (1992). Effects of water immersion on sympathoadrenal and dopa-dopamine systems in humans. Am J Physiol, 262(6 Pt 2), R993-999.

Hardin, A. M., \& Buckner, E. B. (2004). Characteristics of a positive experience for women who have unmedicated childbirth. J Perinat Educ, 13(4), 10-16. doi:10.1624/105812404x6180

Hodnett, E. D. (2002). Pain and women's satisfaction with the experience of childbirth: a systematic review. Am J Obstet Gynecol, 186(5 Suppl Nature), S160-172.

K Cadwell, K. B. (2017). Intrapartum Administration of Synthetic Oxytocin and Downstream Effects on Breastfeeding: Elucidating Physiologic Pathways. Ann Nurs Res Pract,, 2(3).

Karlstrom, A., Nystedt, A., \& Hildingsson, I. (2015). The meaning of a very positive birth experience: focus groups discussions with women. BMC Pregnancy Childbirth, 15, 251. doi:10.1186/s12884-015-0683-0

Krippendorff, K. (2013). Content Analysis- An introduction to its Methodology (3rd ed.). California, USA: SAGE Publications.

Kroll-Desrosiers, A. R., Nephew, B. C., Babb, J. A., Guilarte-Walker, Y., Moore Simas, T. A., \& Deligiannidis, K. M. (2017). Association of peripartum synthetic oxytocin administration and depressive and anxiety disorders within the first postpartum year. Depress Anxiety, 34(2), 137146. doi:10.1002/da.22599

Labour S., Maquire S (2008). The pain of labour. Rev Pain, 2008 Dec 2 (2): 15-19. doi: $10.1177 / 204946370800200205$

Larkin, P., Begley, C. M., \& Devane, D. (2009). Women's experiences of labour and birth: an evolutionary concept analysis. Midwifery, 25(2), e49-59. doi:10.1016/j.midw.2007.07.010

Lavender, T., Walkinshaw, S. A., \& Walton, I. (1999). A prospective study of women's views of factors contributing to a positive birth experience. Midwifery, 15(1), 40-46.

Lindgren, H., \& Erlandsson, K. (2010). Women's experiences of empowerment in a planned home birth: a Swedish population-based study. Birth, 37(4), 309-317. doi:10.1111/j.1523536X.2010.00426.X

Lundgren, I. (2005). Swedish women's experience of childbirth 2 years after birth. Midwifery, 21(4), 346-354. doi:10.1016/j.midw.2005.01.001

Maimburg, R. D., Vaeth, M., \& Dahlen, H. (2016). Women's experience of childbirth - A five year follow-up of the randomised controlled trial "Ready for Child Trial". Women Birth, 29(5), 450-454. doi:10.1016/j.wombi.2016.02.003

Malterud, K., Siersma, V. D., \& Guassora, A. D. (2015). Sample Size in Qualitative Interview Studies: Guided by Information Power. Qual Health Res. doi:10.1177/1049732315617444

Maude, R. M., \& Foureur, M. J. (2007). It's beyond water: stories of women's experience of using water for labour and birth. Women Birth, 20(1), 17-24. doi:10.1016/j.wombi.2006.10.005

McKenna JA., Symon AG. (2014). Water VBAC: exploring a new frontier for women's autonomy. Midwifery, 2014 Jan;30 (1)e 20-5. https://doi.org/10.1016/j.midw.2013.10.004

McKinnon, L. C., Prosser, S. J., \& Miller, Y. D. (2014). What women want: qualitative analysis of consumer evaluations of maternity care in Queensland, Australia. BMC Pregnancy Childbirth, 14, 
366. doi:10.1186/s12884-014-0366-2

Nilsson, C. (2014). The delivery room: is it a safe place? A hermeneutic analysis of women's negative birth experiences. Sex Reprod Healthc, 5(4), 199-204. doi:10.1016/j.srhc.2014.09.010

Pagano, E., De Rota, B., Ferrando, A., Petrinco, M., Merletti, F., \& Gregori, D. (2010). An economic evaluation of water birth: the cost-effectiveness of mother well-being. J Eval Clin Pract, 16(5), 916919. doi:10.1111/j.1365-2753.2009.01220.x

Polit, D., \& Beck, C. T. (2012). Nursing research -Generating and Assessing Evidence for Nursing Practise (Tenth ed.). Philadelphia: Wolters Kluwer.

Prata, N., Tavrow, P., \& Upadhyay, U. (2017). Women's empowerment related to pregnancy and childbirth: introduction to special issue. BMC Pregnancy Childbirth, 17(Suppl 2), 352. doi:10.1186/s12884-017-1490-6

Richmond, H. (2003). Women's experience of waterbirth. Pract Midwife, 6(3), 26-31.

Ulfsdottir, H., Saltvedt, S., \& Georgsson, S. (2017). Waterbirth in Sweden - a comparative study. Acta Obstet Gynecol Scand. doi:10.1111/aogs.13286

Waldenstrom, U. (1999). Experience of labor and birth in 1111 women. J Psychosom Res, 47(5), 471482.

Waldenstrom, U. (2004). Why do some women change their opinion about childbirth over time? Birth, 31(2), 102-107. doi:10.1111/j.0730-7659.2004.00287.x

Walsh, D., \& Devane, D. (2012). A metasynthesis of midwife-led care. Qual Health Res, 22(7), 897910. doi:10.1177/1049732312440330

Weston, C. F., O'Hare, J. P., Evans, J. M., \& Corrall, R. J. (1987). Haemodynamic changes in man during immersion in water at different temperatures. Clin Sci (Lond), 73(6), 613-616.

Wu, C. J., \& Chung, U. L. (2003). The decision-making experience of mothers selecting waterbirth. $J$ Nurs Res, 11(4), 261-268. 